\title{
Solutos orgânicos em genótipos de sorgo forrageiro sob estresse salino
}

\author{
Lucimauro Antonio Alves Oliveira(1), Levy Paes Barreto( ${ }^{(2)}$, Egídio Bezerra Neto(2), \\ Mércia Virgínia Ferreira dos Santos ${ }^{(3)}$ e Jordânia de Cássia Araújo Costa(4)
}

\begin{abstract}
(1)Escola Agrotécnica Federal de Vitória de Santo Antão, Propriedade Terra Preta, s/no, Zona Rural, CEP 55600-000 Vitória de Santo Antão, PE. E-mail: lucimauro@uol.com.br (2)Universidade Federal Rural de Pernambuco (UFRPE), Dep. de Química, Rua Dom Manoel de Medeiros, s/no, Dois Irmãos, CEP 52171-900 Recife, PE. E-mail: levy@ufrpe.br, egidio@ufrpe.br (3)UFRPE, Dep. de Zootecnia. E-mail: mercia@ufrpe.br (4)UFRPE, Dep. de Ciências Florestais. E-mail: jordania.de.araujo@terra.com.br
\end{abstract}

Resumo - O objetivo deste trabalho foi verificar o acúmulo de solutos orgânicos, em materiais genéticos de sorgo sob estresse salino. $\mathrm{O}$ experimento foi realizado em casa de vegetação, em delineamento experimental inteiramente casualizado, organizado em arranjo fatorial entre três índices de salinidade no solo $\left(2,4,10\right.$ e $\left.16 \mathrm{dS} \mathrm{m}^{-1}\right)$ e dez genótipos de sorgo forrageiro (IPA SF-25, IPA 02-03-01, IPA 42-70-02, CSF-4, CSF-5, CSF-6, CSF-7, CSF-8, CSF-9 e CSF-10), com quatro repetições. Os índices de salinidade 10 e $16 \mathrm{dS} \mathrm{m}^{-1}$ incrementaram o teor de carboidratos solúveis totais em 20,2 e 21,3\%, respectivamente. O teor de proteínas solúveis variou entre as cultivares de sorgo em resposta aos índices de salinidade do solo. Os maiores valores de aminoácidos livres totais ocorreram nas plantas submetidas ao índice de salinidade equivalente a $16 \mathrm{dS} \mathrm{m}^{-1}$. Os tratamentos salinos causaram elevação no teor de prolina nos genótipos CSF-5, CSF-6 e CSF-9 (a 10 dS m m$^{-1}$ ) e CSF-10 e CSF-4 (a $16 \mathrm{dS} \mathrm{m}^{-1}$ ). O aumento nos teores de carboidratos solúveis, proteínas solúveis, aminoácidos livres totais e prolina é proporcional ao teor de sal no meio de cultivo e varia com os genótipos estudados.

Termos para indexação: Sorghum bicolor, carboidratos solúveis, proteínas solúveis, salinidade.

\section{Organic solutes in forage sorghum genotypes under saline stress}

\begin{abstract}
The objective of this work was to evaluate the organic compound content in forage sorghum under salt stress condition. The experiment was carried out in a greenhouse with a factorial scheme of $3 \times 10$, in a completely randomized design and four replicates. The evaluated treatments were three levels of soil salinity (2.4, 10 e $16 \mathrm{dS} \mathrm{m}^{-1}$ ) and ten genotypes of forage sorghum (IPA SF-25, IPA 02-03-01, IPA 42-70-02, CSF-4, CSF-5, CSF-6, CSF-7, CSF-8, CSF-9 e CSF-10). There was an increase of 20.2 and 21.3\% in soluble carbohydrates, respectively, for salt treatments of 10 and $16 \mathrm{dS} \mathrm{m}^{-1}$. The content of soluble proteins varied among sorghum cultivars, as a response to salt treatment. The highest values of total free amino acids occurred in plants grown under the salinity level of $16 \mathrm{dS} \mathrm{m}^{-1}$. Saline treatments increased sorghum content of proline for the genotypes CSF-5, CSF-6 and CSF-9 (at $10 \mathrm{dS} \mathrm{m} \mathrm{m}^{-1}$ ), and for CSF-10 and CSF-4 (at $16 \mathrm{dS} \mathrm{m}^{-1}$ ). The increase in soluble carbohydrates, soluble proteins, total free amino acids and free proline content is proportional to soil salinity and varies with the studied genotypes.
\end{abstract}

Index terms: Sorghum bicolor, soluble carbohydrates, soluble proteins, salinity.

\section{Introdução}

O acúmulo de sais solúveis no solo tem limitado a produção agrícola, em regiões áridas e semi-áridas do mundo. O problema atinge cerca de $25 \%$, dos 230 milhões de hectares de área irrigada do globo terrestre (FAO, 2003). As concentrações de sais, em geral, restringem o crescimento tanto da parte aérea como do sistema radicular das plantas, em decorrência de efeitos osmóticos, que podem acarretar déficit hídrico, e efeitos específicos de íons, que resultam em toxidez ou desordens nutricionais (Munns, 2002).

Tem sido verificada a ocorrência de variabilidade genética no sorgo, em relação à tolerância ao estresse salino (Igartua et al., 1995). Algumas respostas fisiológicas, como o acúmulo diferencial de íons tóxicos, de solutos orgânicos e de minerais essenciais nos tecidos foliares explica a existência de genótipos contrastantes (Lacerda et al., 2001). 
O ajustamento osmótico constitui-se num importante mecanismo de tolerância das plantas a condições de baixo potencial hídrico no ambiente radicular, como ocorre em solos salinos. As glicófitas, moderadamente tolerantes à salinidade, retêm grandes quantidades de sais nos caules e nas raízes; assim, o ajuste osmótico nas folhas depende também do acúmulo de solutos orgânicos (Greenway \& Munns, 1980).

O aumento na concentração de compostos orgânicos solúveis, no citoplasma de plantas cultivadas e submetidas a estresse salino, tem sido considerado como um mecanismo utilizado, pelas plantas, para balancear os potenciais osmóticos, entre o citoplasma e o vacúolo, e evitar danos aos sistemas enzimáticos (Munns, 2002), protegendo as estruturas e funções celulares (Barreto, 1997), além de constituir fonte de energia metabólica (Serrano \& Gaxiola, 1994).

O objetivo deste trabalho foi verificar o acúmulo de solutos orgânicos, em genótipos de sorgo forrageiro submetidos a estresse salino.

\section{Material e Métodos}

O experimento foi conduzido em casa de vegetação, no período de setembro a novembro de 2003. Foram utilizadas sementes de dez genótipos de sorgo forrageiro (Sorghum bicolor (L.) Moench), obtidas no banco de germoplasma da Empresa Pernambucana de Pesquisa Agropecuária (IPA).

O delineamento experimental utilizado foi o inteiramente casualizado, organizado em um arranjo fatorial 3x10 (três índices de salinidade no solo e dez genótipos de sorgo forrageiro - IPA SF-25, IPA 02-03-01, IPA 42-70-02, CFS-4, CSF-5, CSF-6, CSF-7, CSF-8, CSF-9 e CSF-10), com quatro repetições. Os índices de salinidade empregados foram equivalentes à condutividade elétrica (CE) de 2,4, 10 e $16 \mathrm{dS} \mathrm{m}^{-1}$, correspondentes, respectivamente, a solo não salino, fortemente salino e muito fortemente salino, segundo Richards (1954).

O solo (0-20 cm) foi coletado da Unidade de Execução de Pesquisa de Itapirema - IPA, Município de Goiana, Zona da Mata, Norte de Pernambuco, classificado como Espodossolo Ferrocárbico, órtico dúrico, A moderado, textura arenosa (92,8\% de areia), álico, fase cerrado, relevo plano (Embrapa, 1999). O solo foi peneirado, secado e colocado em vasos de polietileno com capacidade para $8 \mathrm{~L}$, na quantidade de $7,45 \mathrm{~kg}$ de solo para cada vaso. Uma amostra composta de 10 subamostras foi analisada conforme Embrapa (1997). Com base nos resultados dessa análise, efetuou-se a calagem segundo

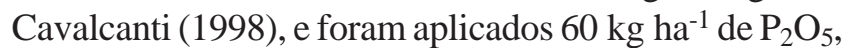
$30 \mathrm{~kg} \mathrm{ha}^{-1}$ de $\mathrm{K}_{2} \mathrm{O}$ e $30 \mathrm{~kg} \mathrm{ha}^{-1}$ de N. A seguir, o solo foi incubado com cloreto de sódio, por 15 dias, para a obtenção dos índices de salinidade correspondentes aos tratamentos, com base na equação de regressão. Trinta dias depois da germinação, fez-se a adubação de cobertura, aplicando-se $60 \mathrm{~kg} \mathrm{ha}^{-1}$ de $\mathrm{N}$.

Na semeadura, foram colocadas dez sementes por vaso, e sete dias depois da emergência, efetuou-se o desbaste, deixando-se duas plantas por vaso. As irrigações foram efetuadas com água mineral, em dias alternados, até drenar, e o drenado foi devolvido ao respectivo vaso. A colheita foi realizada depois de 63 dias do plantio.

$\mathrm{Na}$ colheita, amostras da primeira folha completamente expandida, de cada parcela, foram armazenadas em freezer para posteriores determinações analíticas de carboidratos solúveis, proteínas solúveis, aminoácidos livres totais e prolina, conforme Dubois et al. (1956), Bates et al. (1973) e Bezerra Neto \& Barreto (2004).

Os resultados obtidos foram submetidos à análise estatística, de acordo com Ferreira (2000), utilizando-se o SAS (SAS Institute, 2002). Procedeu-se à análise de variância com teste $\mathrm{F}$ e, na comparação das médias dos tratamentos, aplicou-se o teste de Tukey a 5\% de probabilidade.

\section{Resultados e Discussão}

A interação entre genótipos de sorgo e índices de salinidade não foi significativa para carboidratos solúveis. Não foram observadas diferenças significativas entre os genótipos, quanto aos teores de carboidratos solúveis (Tabela 1).

Embora os genótipos testados não tenham apresentado diferenças significativas no acúmulo de carboidratos solúveis, o aumento da salinidade do solo resultou em acúmulo de carboidratos solúveis nas folhas de sorgo forrageiro (Tabela 1). O aumento nos teores de carboidratos solúveis, observados nos valores de CE de 10 e $16 \mathrm{dS} \mathrm{m}^{-1}$, de 20,2 e 21,3\%, respectivamente, são indicativos da ocorrência de osmorregulação nessas plantas.

Os teores de carboidratos solúveis aumentaram com a salinidade, o que pode ter contribuído para a redução do potencial osmótico foliar, como observado também 
Tabela 1. Teores de carboidratos solúveis da matéria fresca foliar ( $\mathrm{mg} \mathrm{g}^{-1}$ ) de genótipos de sorgo forrageiro, submetidos ao estresse salino durante $63 \operatorname{dias}^{(1)}$.

\begin{tabular}{lcccc}
\hline Genótipo $^{(2)}$ & \multicolumn{4}{c}{ Condutividade elétrica $\left.(\mathrm{dS} \mathrm{m})^{-1}\right)$} \\
\cline { 2 - 5 } & 2,4 & 10 & 16 & Média \\
\hline IPA SF-25 (VC) & 11,28 & 15,49 & 18,90 & $15,22 \mathrm{a}$ \\
IPA 02-03-01 (VC) & 14,22 & 18,24 & 19,80 & $17,42 \mathrm{a}$ \\
IPA 43-70-02 (VC) & 16,46 & 25,67 & 21,14 & $21,09 \mathrm{a}$ \\
CSF-4 (NV) & 16,12 & 20,19 & 20,94 & $19,08 \mathrm{a}$ \\
CSF-5 (NV) & 17,06 & 14,73 & 17,38 & $16,39 \mathrm{a}$ \\
CSF-6 (NV) & 14,99 & 17,17 & 19,34 & $17,17 \mathrm{a}$ \\
CSF-7 (NV) & 20,04 & 20,94 & 17,43 & $19,47 \mathrm{a}$ \\
CSF-8 (NV) & 16,76 & 25,24 & 24,76 & $22,25 \mathrm{a}$ \\
CSF-9 (NV) & 15,97 & 24,49 & 20,11 & $20,52 \mathrm{a}$ \\
CSF-10 (NV) & 14,71 & 14,37 & 20,46 & $16,51 \mathrm{a}$ \\
\hline Média & $15,76 \mathrm{~b}$ & $19,75 \mathrm{a}$ & $20,03 \mathrm{a}$ \\
\hline
\end{tabular}

${ }^{(1)}$ Médias seguidas da mesma letra, nas linhas, não diferem entre si a 5\% de probabilidade, pelo teste de Tukey; o coeficiente de variação foi de 29,64\%. (2)VC: variedade comercial; NV: nova variedade; CSF: cultivar de sorgo forrageiro; pedigree original dos genótipos CSF-4, CSF-5, CSF-6, CSF-7, CSF-8, CSF-9 e CSF-10, respectivamente: 10CA84-B2CA87B2SB88-BCA 89, 25CA84-B2CA87-B1SB88-BCA 89, 38CA84B2CA87-B2SB88-BCA 89, 41CA84-B2CA87-B1SB88-BCA 89, 41CA84-B2CA87-B2SB88-BCA 89, 46CA84-B2CA87-B2SB88BCA 89 e 68CA84-BCA87-01SB88-01SB89.

em outras espécies (Ashraf, 1994). Segundo Ashraf \& Harris (2004), entretanto, o papel dos açúcares, na adaptação de plantas às condições salinas, é insuficiente para a definição de espécies que apresentam tolerância ao sal, em razão das variações interespecíficas e intra-específicas, que são evidentes.

Apesar do aumento, os teores de carboidratos solúveis foram inferiores aos encontrados por El-Haddad \& O'Leary (1994), que constataram aumentos de 30 a 144\%, e Barreto (1997), que encontrou acréscimos de 164\% para genótipo sensível e de $72 \%$ para o genótipo tolerante, sob condutividade elétrica de $10,15 \mathrm{dS} \mathrm{m}^{-1}$. Segundo Lacerda et al. (2001), genótipos de sorgo forrageiro produzem mais carboidratos para o ajustamento osmótico, permitindo assim, condições adequadas para o crescimento da planta. Lacerda et al. (2003) constataram, em folhas de sorgo forrageiro, que ocorreram acréscimos nos teores de carboidratos, quando as plantas foram submetidas a estresse salino de 25 a 51\%, em genótipo tolerante, e de 48 a 68\%, em genótipo sensível.

A combinação de diferentes genótipos de sorgo forrageiro e o incremento da salinidade no solo promoveram interações significativas nos teores de proteínas solúveis, presentes no tecido foliar da planta, durante 63 dias de crescimento (Tabela 2).
Tabela 2. Teores de proteínas solúveis, aminoácidos livres totais e prolina, em genótipos de sorgo forrageiro, submetidos ao estresse salino durante $63 \operatorname{dias}^{(1)}$.

\begin{tabular}{|c|c|c|c|}
\hline \multirow[t]{2}{*}{ Genótipo $^{(2)}$} & \multicolumn{3}{|c|}{ Condutividade elétrica $\left(\mathrm{dS} \mathrm{m}^{-1}\right)$} \\
\hline & 2,4 & 10 & 16 \\
\hline & \multicolumn{3}{|c|}{ Proteínas solúveis $\left(\mathrm{mg} \mathrm{g}^{-1}\right)$} \\
\hline IPA SF-25 (VC) & $1,75 \mathrm{cB}$ & $2,39 \mathrm{bAB}$ & $3,25 \mathrm{aBCD}$ \\
\hline IPA 02-03-01 (VC) & $1,65 \mathrm{bBC}$ & $1,64 \mathrm{bC}$ & $2,73 \mathrm{aCD}$ \\
\hline IPA 43-70-02 (VC) & $1,28 \mathrm{bBCD}$ & $1,74 \mathrm{bCD}$ & $2,53 \mathrm{aD}$ \\
\hline $\mathrm{CSF}-4(\mathrm{NV})$ & $0,56 \mathrm{cE}$ & $1,12 \mathrm{bCD}$ & $4,39 \mathrm{aA}$ \\
\hline CSF-5 (NV) & $0,36 \mathrm{bE}$ & $0,64 \mathrm{bD}$ & $1,58 \mathrm{aE}$ \\
\hline CSF-6 (NV) & $2,69 \mathrm{bA}$ & $3,09 \mathrm{abA}$ & $3,45 \mathrm{aB}$ \\
\hline CSF-7 (NV) & $2,61 \mathrm{bA}$ & $2,78 \mathrm{bA}$ & $3,44 \mathrm{aBC}$ \\
\hline CSF-8 (NV) & $0,78 \mathrm{bDE}$ & $1,43 \mathrm{aC}$ & $1,28 \mathrm{abE}$ \\
\hline CSF-9 (NV) & $1,02 \mathrm{bCDE}$ & $1,28 \mathrm{abCD}$ & $1,65 \mathrm{aE}$ \\
\hline \multirow[t]{2}{*}{ CSF-10 (NV) } & $0,96 \mathrm{bCDE}$ & $1,32 \mathrm{bCD}$ & $2,64 \mathrm{aD}$ \\
\hline & \multicolumn{3}{|c|}{ Aminoácidos livres totais $\left(\mathrm{mg} \mathrm{g}^{-1}\right)$} \\
\hline IPA SF-25 & $0,21 \mathrm{aDE}$ & $0,28 \mathrm{aCD}$ & $0,25 \mathrm{aE}$ \\
\hline IPA $02-03-01$ & $0,20 \mathrm{bE}$ & $0,12 \mathrm{bE}$ & $0,29 \mathrm{aDE}$ \\
\hline IPA $43-70-02$ & $0,50 \mathrm{aA}$ & $32 \mathrm{bCD}$ & $0,54 \mathrm{aB}$ \\
\hline $\mathrm{CSF}-4$ & $0,17 \mathrm{bE}$ & $0,27 \mathrm{aCD}$ & ,25abE \\
\hline CSF-5 & $0,20 \mathrm{bDE}$ & $0,21 \mathrm{bDE}$ & $0,40 \mathrm{aC}$ \\
\hline CSF-6 & $0,38 \mathrm{aABC}$ & $0,28 \mathrm{bCD}$ & $0,39 \mathrm{aCD}$ \\
\hline CSF-7 & $0,42 \mathrm{bAB}$ & $0,48 \mathrm{bA}$ & $0,57 \mathrm{aB}$ \\
\hline CSF-8 & $0,28 \mathrm{bCDE}$ & $0,35 \mathrm{bBC}$ & $0,70 \mathrm{aA}$ \\
\hline CSF-9 & $0,37 \mathrm{bBC}$ & $0,47 \mathrm{aA}$ & $0,54 \mathrm{aB}$ \\
\hline \multirow[t]{2}{*}{ CSF-10 } & $0,31 \mathrm{cBCD}$ & $0,45 \mathrm{bAB}$ & $0,56 \mathrm{aB}$ \\
\hline & \multicolumn{3}{|c|}{ Prolina $\left(\mathrm{g} \mathrm{g}^{-1}\right)$} \\
\hline IPA SF-25 & $18,30 \mathrm{bC}$ & $34,97 \mathrm{bDE}$ & $56,66 \mathrm{aCDEF}$ \\
\hline IPA 02-03-01 & $29,79 \mathrm{aBC}$ & $17,05 \mathrm{aE}$ & $31,86 \mathrm{aF}$ \\
\hline IPA $43-70-02$ & $36,62 \mathrm{aABC}$ & $47,51 \mathrm{aCD}$ & $48,27 \mathrm{aEF}$ \\
\hline CSF-4 & $40,53 \mathrm{bABC}$ & $38,63 \mathrm{bDE}$ & $137,07 \mathrm{aA}$ \\
\hline CSF-5 & $39,06 \mathrm{bABC}$ & $79,49 \mathrm{aAB}$ & $82,80 \mathrm{aBCD}$ \\
\hline CSF-6 & $39,90 \mathrm{bABC}$ & $72,38 \mathrm{aABC}$ & $86,40 \mathrm{aBC}$ \\
\hline CSF-7 & $45,01 \mathrm{aABC}$ & $46,18 \mathrm{aCD}$ & $59,17 \mathrm{aCDE}$ \\
\hline CSF-8 & $60,17 \mathrm{aBA}$ & $50,80 \mathrm{bBCD}$ & $73,81 \mathrm{aBCDE}$ \\
\hline CSF-9 & $58,61 \mathrm{bAB}$ & $85,01 \mathrm{aA}$ & $94,61 \mathrm{aB}$ \\
\hline CSF-10 & $35,59 \mathrm{bABC}$ & $41,26 \mathrm{bDE}$ & $157,21 \mathrm{aA}$ \\
\hline
\end{tabular}

(1)Para cada variável, médias seguidas pelas mesmas letras, minúsculas nas linhas e maiúsculas nas colunas, não diferem entre si a 5\% de probabilidade, pelo teste de Tukey; os coeficientes de variação para proteínas solúveis, aminoácidos livres totais e prolina foram 16,17, 13,35 e $18,48 \%$, respectivamente; VC: variedade comercial; NV: nova variedade; CSF: cultivar de sorgo forrageiro; pedigree original dos genótipos CSF-4, CSF-5, CSF-6, CSF-7, CSF-8, CSF-9 e CSF-10, respectivamente: 10CA84-B2CA87-B2SB88-BCA 89, 25CA84-B2CA87-B1SB88BCA 89, 38CA84-B2CA87-B2SB88-BCA 89, 41CA84-B2CA87B1SB88-BCA 89, 41CA84-B2CA87-B2SB88-BCA 89, 46CA84B2CA87-B2SB88-BCA 89 e 68CA84-BCA87-01SB88-01SB89.

A interação entre os teores de sal e os genótipos evidenciou variações genotípicas entre as cultivares de sorgo, na produção de proteínas solúveis, dependente dos índices de CE do solo. Na CE de 2,4 dS m-1, os maiores teores de proteínas solúveis foram observados nos genótipos CSF-6 e CSF-7, o que também foi verificado na CE de $10 \mathrm{dS} \mathrm{m}{ }^{-1}$. O genótipo IPA SF-25 apresen- 
tou o mesmo teor de proteína dos genótipos CSF-6 e CSF-7 na CE de $10 \mathrm{dS} \mathrm{m}^{-1}$. As respostas dos genótipos foram alteradas na CE de $16 \mathrm{dS} \mathrm{m}{ }^{-1}$, em que o CSF-4 apresentou teor de proteínas solúveis superior a todos os outros. Para o CSF-4, o aumento da CE do solo, de 2,4 para $16 \mathrm{dS} \mathrm{m}^{-1}$, resultou em incremento de aproximadamente sete vezes no teor de proteínas solúveis do tecido foliar da planta.

Na maioria dos genótipos, ocorreu aumento dos teores de proteínas solúveis, em consequiência da salinidade, principalmente a $16 \mathrm{dS} \mathrm{m}^{-1}$, tendo havido poucas diferenças entre os índices de 2,4 e $10 \mathrm{dS} \mathrm{m} \mathrm{m}^{-1}$, observando-se aumento significativo apenas no genótipo CSF-8 (Tabela 2). O genótipo IPA SF-25 apresentou incremento no teor de proteínas proporcional ao aumento da salinidade. O genótipo IPA 02-03-01 não apresentou aumento nos teores de proteínas solúveis nos índices de CE de 2,4 e $10 \mathrm{dS} \mathrm{m}^{-1}$.

As interações dos teores de aminoácidos livres totais também demonstraram interação significativa entre índices de salinidade e os genótipos do sorgo testados (Tabela 2). Os teores de aminoácidos livres totais aumentaram, de modo significativo, no genótipo CSF-9, a partir da CE de $10 \mathrm{dS} \mathrm{m}^{-1}$, proporcionalmente ao aumento de salinidade do solo, mas esse aumento não continuou na CE mais elevada. Os teores de aminoácidos livres totais, no genótipo IPA SF-25, não se modificaram com o incremento da salinidade. No genótipo IPA 43-70-02, verificou-se o menor valor de aminoácidos livres totais, e o genótipo CSF-6 não se diferenciou dos genótipos CSF-5, CSF-4 e IPA SF-25.

À salinidade de 2,4 dS m-1, os genótipos IPA 43-70-02, CSF-6 e CSF-7 apresentaram teores médios de aminoácidos livres totais superiores entre os materiais de sorgo forrageiro. O aumento da CE do solo para $10 \mathrm{dS} \mathrm{m}^{-1}$ destacou os genótipos CSF-7 e CSF-9, que apresentaram os maiores valores nos teores de aminoácidos livres totais. Entretanto, à salinidade de $16 \mathrm{dS} \mathrm{m}{ }^{-1}$, o genótipo CSF-8 foi o que apresentou o maior teor desse soluto orgânico. Os genótipos CSF-4 e CSF-9 responderam com incremento no teor de aminoácidos livres totais, quando foram submetidos à salinidade de $10 \mathrm{dS} \mathrm{m}^{-1}$; os genótipos IPA 02-03-01, CSF-5, CSF-7, CSF-8 e CSF-10 somente o fizeram a $16 \mathrm{dS} \mathrm{m}^{-1}$. O aumento da concentração de aminoácidos livres totais pode ter ocorrido, principalmente, como resultante do aumento na biossíntese desses compostos, uma vez que houve elevação no teor de proteínas solúveis, com o estresse salino.
Aminoácidos e carboidratos solúveis são considerados os principais solutos orgânicos, para o ajustamento osmótico de plantas submetidas a estresse hídrico e salino (Saneoka et al., 1995). Os resultados do presente trabalho corroboram os de Lacerda et al. (2001), que verificaram acréscimos na concentração de aminoácidos livres totais em plantas de sorgo forrageiro, em solução salina com 10,15 dS m-1.

A interação entre os teores de prolina, os índices de salinidade do solo e os genótipos de sorgo forrageiro avaliados foi, também, estatisticamente significativa (Tabela 2).

Nos genótipos IPA 02-03-01, IPA 43-70-02 e CSF-7, não foram identificadas variações nos teores de prolina com o incremento da CE do solo, e os valores determinados permaneceram estatisticamente iguais. Os genótipos CSF-5, CSF-6 e CSF-9, com o aumento dos índices de salinidade do solo, tiveram os maiores teores de prolina, a partir da CE de $10 \mathrm{dS} \mathrm{m}^{-1}$, que porém, não se intensificou na CE de $16 \mathrm{dS} \mathrm{m}^{-1}$. Os genótipos IPA SF-25, CSF-4 e CSF-10 só apresentaram incremento nos teores de prolina no índice mais elevado de CE do solo.

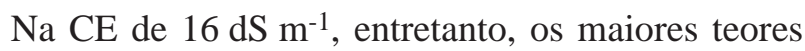
de prolina foram encontrados nos genótipos CSF-10 e CSF-4.

A perda da turgescência, pela célula, parece ser o acontecimento inicial que desencadeia uma seqüência complexa de eventos adaptativos e resulta no acúmulo de prolina, sob estresse hídrico ou salino (Greenway \& Munns, 1980), para promover a diminuição no potencial osmótico no tecido (Hanson et al., 1977).

Embora alguns trabalhos evidenciem a importância no incremento de prolina para a tolerância à salinidade (Rosa-Ibarra \& Maiti, 1995), é incerta a sua significância, tendo em vista que os estresses bióticos e abióticos promovem, também, o acréscimo de prolina (Mumtaz et al., 1995). Ressalta-se ainda que, em muitos trabalhos, a relação entre acúmulo de prolina e tolerância ao estresse tem demonstrado resultados inversos (Lutts et al., 1996).

\section{Conclusão}

O aumento na concentração de carboidratos solúveis, proteínas solúveis, aminoácidos livres totais e prolina, no tecido foliar de sorgo forrageiro, é proporcional ao teor de sal no meio de cultivo e varia com o genótipo estudado. 


\section{Agradecimentos}

À Universidade Federal Rural de Pernambuco e à Capes, pelo suporte financeiro; à Empresa Pernambucana de Pesquisa Agropecuária (IPA), pelas sementes dos materiais genéticos e solo utilizado; ao CNPq, pelo suporte financeiro e pela bolsa concedida a Mércia Virgínia Ferreira dos Santos.

\section{Referências}

ASHRAF, M. Organic substances responsible for salt tolerance in Eruca sativa. Biologia Plantarum, v.26, p.255-259, 1994.

ASHRAF, M.; HARRIS, P.J.C. Potential biochemical indicators of salinity tolerance in plants. Plant Science, v.166, p.3-16, 2004.

BARRETO, L.P. Estudo nutricional e bioquímico do sorgo (Sorghum bicolor (L.) Moench) sob estresse salino. 1997. 179p. Tese (Doutorado) - Universidade Federal Rural de Pernambuco, Recife.

BATES, L.S.; WALDREN, R.P.; TEARE, J.D. Rapid determination of free proline for water-stress studies. Plant Soil, v.39, p.205-207, 1973.

BEZERRA NETO, E.; BARRETO, L.P. Métodos de análises químicas em plantas. Recife: UFRPE, 2004. 148p.

CAVALCANTI, F.J. de A. (Coord.). Recomendações de adubação para o Estado de Pernambuco: 2a aproximação. Recife: IPA, 1998. 198p.

DUBOIS, M.; GILLES, K.A.; HAMILTON, J.K.; REBERS, P.A.; SMITH, F. Colorimetric method for determinations of sugars and related substances. Analytical Chemistry, v.28, p.350-356, 1956.

EL-HADDAD, E.H.M.; O’LEARY, J.W. Effect of salinity and K/ Na ratio of irrigation water on growth and solute content of Atriplex amnicola and Sorghum bicolor. Irrigation Science, v.14, p.127133, 1994.

EMBRAPA. Centro Nacional de Pesquisa de Solos (Rio de Janeiro, RJ). Sistema brasileiro de classificação de solos. Brasília, 1999. 412p.

EMBRAPA. Serviço Nacional de Levantamento e Conservação do Solo. (Rio de Janeiro, RJ). Manual de métodos de análises do solo. Rio de Janeiro, 1997. 212p.

FAO. Extent and causes of salt-affected soils in participating countries. Disponível em: <http://www.fao.org/ag/agl/agll/spush/ topic2.htm>. Acesso em: 20 maio 2003.
FERREIRA, P.V. Estatística experimental aplicada à Agronomia. Maceió: Edufal, 2000. 437p.

GREENWAY, H.; MUNNS, R. Mechanisms of salt tolerance in nonhalophytes. Annual Review of Plant Physiology, v.31, p.149190, 1980.

HANSON, A.; NELSEN, C.E.; EVERSON, E.H. Evaluation of free proline accumulation as an index of drought resistance using two contrasting barley cultivars. Crop Science, v.17, p.720-726, 1977.

IGARTUA, E.; GRACIA, M.P.; LASA, J.M. Field responses of grain sorghum to a salinity gradient. Field Crops Research, v.42, p.15-25, 1995.

LACERDA, C.F.; CAMBRAIA, J.; CANO, M.A.O.; RUIZ, H.A. Plant growth and solute accumulation and distribution in two sorghum genotypes, under $\mathrm{NaCl}$ stress. Revista Brasileira de Fisiologia Vegetal, v.13, p.270-284, 2001.

LACERDA, C.F.; CAMBRAIA, J.; CANO, M.A.O.; RUIZ, H.A. Solute accumulation and distribution during shoot and leaf development in two sorghum genotypes under salt stress. Environmental and Experimental Botany, v.49, p.107-120, 2003.

LUTTS, S.; KINET, J.M.; BOUHARMONT, J. Effects of salt stress on growth, mineral nutrition and proline accumulation in relation to osmotic adjustment in rice (Oryza sativa L.) cultivars differing in salinity resistance. Journal of Plant Growth Regulation, v.19, p.207-218, 1996.

MUMTAZ, S.; NAQVI, S.S.M.; SHERREN, A.; KHAN, M.A. Proline accumulation in wheat seedlings subjected to various stresses. Acta Physiologial Plantarum, v.17, p.17-20, 1995.

MUNNS, R. Comparative physiology of salt and water stress. Plant, Cell and Environment, v.25, p.239-250, 2002.

RICHARDS, L.A. (Ed.). Diagnosis and improvement of saline and alkali soils. Washington: United States Salinity Laboratory, 1954. 160p. (USDA. Agriculture handbook, 60).

ROSA-IBARRA, M. de la; MAITI, R.K. Biochemical mechanism in glossy sorghum lines for resistance to salinity stress. Plant Physiology, v.146, p.515-519, 1995.

SANEOKA, H.; NAGASAKA, C.; HAHN, D.T.; YANG, W.J.; PREMACHANDRA, G.S.; JOLY, R.J.; RHODES, D. Salt tolerance of glycinebetaine-deficient and -containing maize lines. Plant Physiology, v.107, p.631-638, 1995.

SAS INSTITUTE (Cary, Estados Unidos). SAS software: user's guide, version 8.0. Cary, 2002. 291p.

SERRANO, R.; GRAXIOLA, R. Microbial models and salt stress tolerance in plants. Critical Reviews in Plant Sciences, v.13, p.121-138, 1994.

Recebido em 25 de novembro de 2004 e aprovado em 8 de junho de 2005 